\title{
Physical activity in patients with type 2 diabetes and hypertension - insights into motivations and barriers from the MOBILE study
}

This article was published in the following Dove Press journal:

Vascular Health and Risk Management

29 June 2015

Number of times this article has been viewed

\author{
Martine Duclos ${ }^{1,2}$ \\ Sylvie Dejager ${ }^{3,4}$ \\ Nicolas Postel-Vinay ${ }^{5}$ \\ Sylvie di Nicola ${ }^{6}$ \\ Stéphane Quéré7 \\ Béatrice Fiquet ${ }^{4,5}$ \\ 'Department of Sport Medicine and \\ Functional Explorations, University- \\ Hospital (CHU), G Montpied \\ Hospital; INRA, UNH, CRNH \\ Auvergne, ${ }^{2}$ Nutrition Department, \\ University of Auvergne, Clermont- \\ Ferrand, Auvergne, ${ }^{3}$ Department \\ of Endocrinology and Metabolism, \\ La Pitié-Salpétrière Hospital, \\ Paris, ${ }^{4}$ Clinical and Scientific \\ Affairs, Novartis Pharma SAS, \\ Rueil-Malmaison, ${ }^{5}$ Department of \\ Hypertension, Georges Pompidou \\ European Hospital, Paris, ${ }^{6}$ Biostatistics, \\ Inferential, Paris, ${ }^{7}$ Biostatistics, \\ Novartis Pharma SAS, Rueil- \\ Malmaison, France
}

Correspondence: Sylvie Dejager

Department of Endocrinology and Metabolism, La Pitié-Salpétrière Hospital, 47-83 Boulevard de l'Hôpital,

75013 Paris, France

Tel +33 | 42177832

Email sylvie.dejager@psl.aphp.fr
Background: Although physical activity (PA) is key in the management of type 2 diabetes (T2DM) and hypertension, it is difficult to implement in practice.

Methods: Cross-sectional, observational study. Participating physicians were asked to recruit two active and four inactive patients, screened with the Ricci-Gagnon (RG) self-questionnaire (active if score $\geq 16$ ). Patients subsequently completed the International Physical Activity Questionnaire. The objective was to assess the achievement of individualized glycated hemoglobin and blood pressure goals $(<140 / 90 \mathrm{mmHg})$ in the active vs inactive cohort, to explore the correlates for meeting both targets by multivariate analysis, and to examine the barriers and motivations to engage in PA.

Results: About 1,766 patients were analyzed. Active $(n=628)$ vs inactive $(n=1,138)$ patients were more often male, younger, less obese, had shorter durations of diabetes, fewer complications and other health issues, such as osteoarticular disorders $(P<0.001$ for all). Their diabetes and hypertension control was better and obtained despite a lower treatment burden. The biggest difference in PA between the active vs inactive patients was the percentage who declared engaging in regular leisure-type PA ( $97.9 \%$ vs $9.6 \%$ ), also reflected in the percentage with vigorous activities in International Physical Activity Questionnaire (59.5\% vs 9.6\%). Target control was achieved by $33 \%$ of active and $19 \%$ of inactive patients $(P<0.001)$. Active patients, those with fewer barriers to PA, with lower treatment burden, and with an active physician, were more likely to reach targets. The physician's role emerged in the motivations (reassurance on health issues, training on hypoglycemia risk, and prescription/monitoring of the PA by the physician). A negative self-image was the highest ranked barrier for the inactive patients, followed by lack of support and medical concerns.

Conclusion: Physicians should consider PA prescription as seriously as any drug prescription, and take into account motivations and barriers to PA to tailor advice to patients' specific needs and reduce their perceived constraints.

Keywords: physical activity, type 2 diabetes, hypertension, motivations, barriers, MOBILE

\section{Introduction}

Achieving recommended levels of physical activity (PA) is a public health priority, and the first-line measure in the management of many chronic diseases, ${ }^{1,2}$ in particular type 2 diabetes (T2DM) ${ }^{3,4}$ and hypertension. ${ }^{5}$

Physical inactivity is one of the main risk factors, just above smoking, for noncommunicable diseases around the world, thus representing a major burden on health care. ${ }^{6}$ Recent data from the European Prospective Investigation into Cancer and Nutrition study in over 334,000 European men and women suggest that twice as many deaths 
may be attributable to physical inactivity compared with the number of deaths attributable to obesity. ${ }^{7}$

A large prospective study conducted among 252,925 persons from the National Institutes of Health-American Association of Retired Persons Diet and Health Study showed that following PA guidelines was associated with a substantially lower risk of death (relative risk [RR], 0.50; 95\% confidence interval [CI], 0.46-0.54). Importantly, engaging in PA even at less than recommended levels was also related to reduced mortality risk (RR, $0.81 ; 95 \% \mathrm{CI}, 0.76-0.86){ }^{8}$

This beneficial effect on mortality was linked to the marked improvement in all cardiovascular risk factors and in particular diabetes and hypertension. ${ }^{8}$ Furthermore, it has been well demonstrated that PA is an effective nonpharmacological intervention to improve diabetes control and to reduce high blood pressure $(\mathrm{BP})$ and should be an integral component of the care strategy. ${ }^{4,5}$

However in clinical practice, many patients with known T2DM and hypertension, often overweight or obese and with other comorbidities, do not achieve recommended levels of PA, ie, at least 30 minutes of moderate PA five times a week. ${ }^{3,5}$

In the MOtivations and BarrIers to Physical Activity in patiEnts with type 2 diabetes and hypertension (MOBILE) study, we set out to examine active and inactive populations with T2DM and hypertension, and to look into the barriers and motivations to engage in PA as expressed by active and inactive patients. We assessed the proportion of patients controlled for diabetes and hypertension among the active and inactive cohorts. Finally, we explored correlates for meeting the targets for glycemic and BP control and to further investigate the role of the physicians.

\section{Methods}

\section{Study design and participants}

MOBILE was a cross-sectional, observational French study conducted during the first half of 2014. Over 6,000 physicians (about two-thirds cardiologists and one-third diabetologists [DB]) were invited to participate in the study, 317 accepted and 258 actively recruited patients. Participating physicians (cardiologists and DB) were asked to recruit six consecutive patients with T2DM and hypertension: two active and four inactive patients, on the basis of an initial screening with the Ricci-Gagnon (RG) self-questionnaire (active defined as RG total score $\geq 16$ ). Men and women aged $\geq 18$ years, diagnosed with T2DM and with pharmacologically treated hypertension for whom a recent glycated hemoglobin $\left(\mathrm{HbA}_{1 c}\right)$ value was available ( $<4$ months), were included in the study. Patients with secondary forms of diabetes or hypertension, treated with lifestyle intervention only, with absolute contraindication to PA or unable to reliably complete self-questionnaires, and female patients who were either pregnant or breast-feeding were excluded from the study.

The primary objective of the study was to evaluate the percentage of patients achieving both their individualized glycemic target and their BP goal in the two cohorts of active and inactive patients. Targets for glycemic and BP control were defined as follows: individualized preset objective for $\mathrm{HbA}_{1 \mathrm{c}}$ according to current recommendations and $\mathrm{BP}<140 / 90 \mathrm{mmHg}$ or average ambulatory $\mathrm{BP}<135 / 85 \mathrm{mmHg}$. We investigated variables independently associated with the control of both diabetes and hypertension.

Patients included in each cohort subsequently completed the validated short version (nine-item) of the International Physical Activity Questionnaire (IPAQ-SF). ${ }^{9}$ All the physicians also completed the IPAQ-SF to assess their own level of PA. The IPAQ-SF form records three types of activities (vigorous PA such as aerobics, moderate-intensity activity such as leisure cycling, walking) and time spent sitting. Only activities lasting $\geq 10$ minutes at a time were taken into account. Responses were converted to metabolic equivalent task minutes per week (MET-min/wk) according to the IPAQ scoring protocol: total minutes over the last 7 days spent on vigorous activity, moderate-intensity activity, and walking were multiplied by the energy cost of each activity: $8.0 \mathrm{MET}$, 4.0 MET and 3.3 MET for vigorous, moderate, and walking, respectively. Total MET scores across the three subcomponents (vigorous + moderate + walking) were summed to indicate overall PA. ${ }^{9}$ The threshold for active versus inactive individuals was then defined on the basis of current guidelines for $\mathrm{PA},{ }^{3,10}$ recommending at least 30 minutes of moderate PA five times a week: 30 minutes $\times$ factor $4 \times 5$ times per week $=600 \mathrm{MET}-\mathrm{min} / \mathrm{wk}$. Individuals could be classified as active (meeting PA recommendations $\geq 600 \mathrm{MET}-\mathrm{min} / \mathrm{wk}$ ) or inactive (if PA $<600 \mathrm{MET}-\mathrm{min} / \mathrm{wk}$ ) according to their answers to the IPAQ-SF questionnaire. In addition, the IPAQSF allowed further insight into sedentary behaviors.

We compared the sociodemographic and clinical characteristics of the cohorts screened as active vs inactive via the RG. Further, we assessed their PA as collected with the RG and IPAQ-SF in detail and the breakdown of total PA in different domains. All analyses were also conducted in the cohorts of patients re-classified as active and inactive according to the IPAQ-SF questionnaire.

To gain insight into potential barriers and motivations to PA in this population, active and inactive patients according to both RG and IPAQ-SF questionnaires also completed 
self-questionnaires to evaluate and rank, on a scale of 1 ("fully disagree") to 5 ("fully agree"), barriers limiting their PA and motivations enabling regular PA. Barrier items were classified into four main categories: fitness and self-image (feeling too tired, too fat, not feeling like it, feeling unfit, feeling self-conscious about one's looks); lack of support from someone other than a physician (nobody to exercise with, nobody encouraging); health concerns (fear of hypoglycemia, fear of BP rise, musculoskeletal disorders, fear of heart attack, fear of injury); and environmental factors (lack of infrastructures close by, lack of parks close by, lack of time, too costly). Motivation items were grouped into five main categories: confidence in their health (absence of fear of medical risk; trained and reassured on how to prevent hypoglycemia); medical advice and support (direct request from the physician, regular monitoring of their PA from the physician); encouragement and support from someone other than a physician (someone to exercise with, someone encouraging); self-image (having sufficiently lost weight); and environmental factors (sufficient infrastructures/parks available close by, pedometer to use, Internet or smartphone devices, advice from a coach, sufficient time).

Physicians were also requested to complete a questionnaire about how they prescribe PA in routine practice.

\section{Data analysis/statistical analysis}

Sample size was set to guarantee sufficient accuracy $( \pm 5 \%)$ of the $95 \%$ bilateral CI of the difference in the proportions of patients achieving their combined BP and glycemic target (primary end point of the study). All analyses were performed on the analyzable population, defined as all included patients respecting the selection criteria.

Descriptive statistics were computed for all collected data, including physicians' information, BP and diabetes patient data, RG self-questionnaire, and IPAQ-SF subcomponent and overall PA scores. Quantitative variables are presented with mean \pm standard deviation and/or with median and range where appropriate. Qualitative variables are presented with absolute frequency and percentage per answer category. Comparisons between active and inactive patients defined on the basis of the RG self-questionnaire were additionally performed for all data by means of chi-square test (categorical variables) and Student's $t$-test (quantitative variables).

Univariate comparisons between patients achieving or not their combined BP and glycemic target (primary end point) were performed using the chi-square test or Student's $t$-test, as appropriate, according to demographic and baseline characteristics. Each characteristic with a $P$-value $<0.2$ resulting from these comparisons was entered into a stepwise multivariate logistic regression analysis to identify factors associated with the control of both diabetes and hypertension. $P$-values $<0.05$ were used to indicate statistical significance in the final multivariate analysis, which included the active status of the patients according to the RG self-questionnaire.

Pearson correlation coefficients and coefficients of determination $\left(R^{2}\right)$ between questionnaire scores (eg, IPAQ-SF sedentary vs total score) were computed for exploratory purpose.

Missing data were not replaced. All statistical tests were carried out at the two-sided 5\% significance level. Statistical analyses were performed using $\mathrm{SAS}^{\circledR}$ software version 9.2 (SAS Institute Inc., Cary, NC, USA).

\section{Ethics}

This observational study was conducted in accordance with the rules of the French Order of Physicians and Good Practices for Epidemiological Studies. Candidates for inclusion were provided with full information about the study in writing. All data processing was carried out in compliance with French Information Technology and Privacy Law.

\section{Results}

\section{Patient recruitment}

In total, 126 cardiologists and $132 \mathrm{DB}$ included 2,047 patients: 281 were excluded for not meeting all the inclusion criteria, and 1,766 patients were retained in the final analysis. The 1,766 patients were entered into two cohorts according to $R G$ scores: 628 in the active cohort (with an RG score $\geq 16$ ) and 1,138 in the inactive cohort (with an RG score $<16$ ).

Physicians had a mean age of $52.2 \pm 9.3$ years, $53 \%$ were male (predominantly male for cardiologists [80\%] but not for DB [30\%]) and were mostly physically active (7\% had an IPAQ-SF score $<600$ MET-min/wk, with a mean of $316 \pm 163$ MET-min/wk and 93\% had an IPAQ-SF $\geq 600$ MET-min/ wk, with a mean of 2,673 $\pm 1,984$ MET-min/wk).

\section{Sociodemographic and clinical characteristics of the population}

Patients entered in the active vs the inactive cohort were more often male, of younger age $(23.2 \%$ vs $13.7 \%$ were $<55$ years and $38.9 \%$ vs $54.1 \%$ were $\geq 65$ years old), had a lower mean body mass index (BMI), and were less likely to be obese, morbidly obese (BMI $\geq 35 \mathrm{~kg} / \mathrm{m}^{2}$ in $9.8 \%$ vs $24.7 \%$ ), or have abdominal obesity ( $46.6 \%$ vs $69.8 \%$ for male with waist circumference $\geq 102 \mathrm{~cm}$, and $74.3 \%$ vs $86.5 \%$ for female with waist circumference $\geq 88 \mathrm{~cm} ; P<0.001)$. In terms 
of socioprofessional characteristics, a significantly larger percentage of active individuals were in the higher senior manager category $(17.0 \%$ vs $9.9 \%)$ and a smaller percentage were without profession ( $9.0 \%$ vs $17.8 \%)$.

The disease was less advanced in patients of the active cohort, with a smaller percentage of individuals with a diabetes duration $>10$ years $(41.7 \%$ vs $51.1 \%)$ and hypertension $>10$ years $(37.1 \%$ vs $50.5 \%)$ and a smaller percentage with diabetes complications $(22.9 \%$ micro- and $25.5 \%$ macrovascular vs $39.7 \%$ and $33.9 \%$, respectively). The percentage of patients reporting other health issues, such as musculoskeletal disorders, was also markedly lower in the active cohort ( $15.1 \%$ vs $43.9 \%)(P<0.001$ for all).

Diabetes control was better in patients of the active cohort (mean $\mathrm{HbA}_{1 \mathrm{c}}$ of $7.1 \%$ vs $7.5 \%$, and $55.6 \%$ of active patients with $\mathrm{HbA}_{1 \mathrm{c}}<7.0 \%$ vs $37.2 \%$ ) as was control of hypertension (mean of 133/77 mmHg vs $137 / 79 \mathrm{mmHg}$, and $65.4 \%$ of active patients with $\mathrm{BP}<140 / 90 \mathrm{mmHg}$ vs $51.2 \%$ ). This better control was obtained despite a lower treatment burden: on average 1.9 antidiabetic (vs 2.1) and 1.9 antihypertensive drugs (vs 2.2) and less use of insulin (21.0\% of active patients were on insulin vs $29.7 \%$ ); more active patients were on monotherapy for diabetes $(39.2 \%$ vs $28.9 \%)$ and for hypertension (43.9\% vs 27.2\%), respectively (Table 1 ).

All these characteristics and differences between active and inactive patients were also observed when patients were re-classified according to the IPAQ-SF questionnaire (data not shown).

\section{PA scores of the population}

RG self-questionnaire

The active population had more work-related activity (intensity quoted $\geq 3$, ie, at least moderate or vigorous in $41.1 \% \mathrm{vs}$ $10.8 \%$ of individuals) as well as household daily activities ( $\geq 5 \mathrm{~h} / \mathrm{wk}$ in $54.1 \%$ vs $28.1 \%$ of individuals), walked significantly more (walking $>30 \mathrm{~min} / \mathrm{d}$ in $67.2 \%$ vs $25.2 \%$ of individuals), and climbed more stairs a day (31.8\% vs $11.1 \%$ declared climbing $\geq 6$ stairs/d; $P<0.001$ for all). The biggest difference between the two cohorts was the percentage of active individuals who declared engaging in a regular exercise or leisure-type PA $(97.9 \%$ vs $9.6 \%$ of inactive patients). On average, the active cohort had a mean total $\mathrm{RG}$ score of 24.6 points (vs 8.6) with 10.2 points coming from daily activities (vs 6.9) and 14.4 points from exercise and leisure-type PA (vs 1.7) (Table 2).

\section{IPAQ-SF questionnaire}

The total PA energy expenditure measured by IPAQ-SF was 4,701 MET-min/wk in the active vs 1,601 MET-min/wk in the inactive cohort. While all PA-type scores were consistently higher across the board, the main difference characterizing active vs inactive patients was driven by the patients engaging in vigorous activities (59.5\% vs $9.6 \%$ of individuals declaring doing so). The mean score of vigorous PA was 2,053 vs 282 MET-min/wk (and median, 960 vs 0), that of moderate PA was 1,468 vs $692 \mathrm{MET}$-min/wk (median, 960 vs 240), and walking represented 1,243 vs 631 MET-min/wk (median, 891 vs 347).

Most of the patients classified as active via the $\mathrm{RG}$ had a total PA energy expenditure measured by IPAQ-SF above the threshold of 1,500 MET-min/wk (79.9\%), and 17.3\% had a score between 600 and 1,500 MET-min/wk, with barely any $(2.8 \%)$ below $600 \mathrm{MET}-\mathrm{min} / \mathrm{wk}$. In the inactive cohort, however, $41.0 \%$ of patients had an IPAQ-SF score $<600$ MET-min/wk and only $31.0 \%$ of patients had an IPAQ-SF score $\geq 1,500 \mathrm{MET}-\mathrm{min} / \mathrm{wk}$.

Sitting time was also significantly different between the two cohorts, with $37.8 \%$ of the active patients classified as sedentary ( sitting time $\geq 8 \mathrm{~h} / \mathrm{d}$ ) vs $64.2 \%$ of the inactive patients; mean time spent sitting was $7.2 \mathrm{~h} / \mathrm{d}$ (median, 7.0) vs $9.3 \mathrm{~h} / \mathrm{d}$ (median, 9.0) $(P<0.001)$. The breakdown of activities while sitting was also different. The inactive cohort spent more time watching television (TV) both during the week (184 min/d [median, 180] vs $130 \mathrm{~min} / \mathrm{d}$ [median, 120]) and at weekends (206 min/d [median, 180] vs $150 \mathrm{~min} / \mathrm{d}$ [median, 120]) (all $P<0.001$ ). Conversely, the active cohort spent more time at their computer both during the week (75 min/d [median, 60] vs $62 \mathrm{~min} / \mathrm{d}$ [median, 10]; $P=0.013)$ and at weekends (53 $\mathrm{min} / \mathrm{d}$ [median, 30] vs $48 \mathrm{~min} / \mathrm{d}$ [median, 0]; $P=0.1$ ).

In the overall population, the sedentary score (mean time spent sitting) was inversely correlated with the total IPAQ-SF score: the Pearson correlation coefficient was $-0.32\left(\mathrm{R}^{2} 0.11\right)$.

\section{Percentage of patients at goal for $\mathrm{HbA}_{\mathrm{Ic}}$ and $\mathrm{BP}$ and multivariate analysis of predictive factors}

In the active cohort, $45.9 \%$ and $67.8 \%$ of the patients were at target for the control of $\mathrm{HbA}_{1 \mathrm{c}}$ and $\mathrm{BP}$, respectively, vs $33.1 \%$ and $54.0 \%$ of those in the inactive cohort (both $P<0.001)$. The control of both targets was achieved by, respectively, $32.8 \%$ of active and $19.3 \%$ of inactive patients $(P<0.001)$.

In multivariate analysis, factors significantly and independently associated with the control of both diabetes and hypertension are shown in Figure 1. Patients having achieved the combined glycemic and BP goal were more likely to be 
Table I Demographic and clinical characteristics of the patients in the active and inactive cohorts

\begin{tabular}{|c|c|c|c|}
\hline & $\begin{array}{l}\text { Active patients, } \\
\text { RG } \geq 16(\mathrm{~N}=628)\end{array}$ & $\begin{array}{l}\text { Inactive patients, } \\
\text { RG }<16(\mathbf{N}=1,138)\end{array}$ & $P$-value \\
\hline Sex, male (\%) & 70.7 & 56.2 & $<0.001$ \\
\hline Age, mean $\pm S D(y r)$ & $61.6 \pm 9.9$ & $65.3 \pm 10.1$ & $<0.001$ \\
\hline $\mathrm{BMI}$, mean $\pm \mathrm{SD}\left(\mathrm{kg} / \mathrm{m}^{2}\right)$ & $28.6 \pm 4.7$ & $31.7 \pm 5.8$ & $<0.001$ \\
\hline Obese $\left(\%\right.$ with $\left.\mathrm{BMI} \geq 30 \mathrm{~kg} / \mathrm{m}^{2}\right)$ & 33.5 & 58.0 & $<0.001$ \\
\hline \multicolumn{4}{|l|}{ Waist circumference } \\
\hline Male, mean $\pm S D(\mathrm{~cm})$ & $102.2 \pm 13.0$ & $109.5 \pm 13.4$ & $<0.001$ \\
\hline Female, mean \pm SD $(\mathrm{cm})$ & $95.5 \pm 13.6$ & $102.8 \pm 14.2$ & $<0.001$ \\
\hline Waist $\geq 102 \mathrm{~cm}$ (male) (\%) & 46.6 & 69.8 & $<0.001$ \\
\hline Waist $\geq 88 \mathrm{~cm}$ (female) (\%) & 74.3 & 86.5 & $<0.001$ \\
\hline SPC (\%) & & & $<0.001$ \\
\hline Self-employed & 8.2 & 10.7 & \\
\hline Farmer & 4.0 & 5.0 & \\
\hline Worker & 13.2 & 13.9 & \\
\hline Employee & 29.2 & 29.9 & \\
\hline Middle manager & 19.2 & 12.8 & \\
\hline Senior manager & 17.0 & 9.9 & \\
\hline No profession & 9.0 & 17.8 & \\
\hline Living alone (\%) & 10.0 & 14.1 & 0.015 \\
\hline Duration of diabetes (\%) & & & $<0.001$ \\
\hline$<\mathrm{I} \mathrm{yr}$ & 4.0 & 2.3 & \\
\hline $1-5 y r$ & 29.9 & 17.9 & \\
\hline $5-10 \mathrm{yr}$ & 24.4 & 28.7 & \\
\hline$>10 \mathrm{yr}$ & 41.7 & 51.1 & \\
\hline Number of antidiabetics, mean \pm SD (including insulin) & $1.9 \pm 0.8$ & $2.1 \pm 0.9$ & $<0.001$ \\
\hline$\%$ in monotherapy & 39.2 & 28.9 & $<0.001$ \\
\hline$\%$ in dual therapy & 37.9 & 41.6 & $<0.001$ \\
\hline$\%$ in triple therapy or more & 22.9 & 29.5 & $<0.001$ \\
\hline$\%$ with insulin ( \pm OAD) & 21.0 & 29.7 & $<0.001$ \\
\hline $\mathrm{HbA}_{\mathrm{Ic}}$, mean $\pm \mathrm{SD}$ & $7.1 \pm 0.9$ & $7.5 \pm 1.2$ & $<0.001$ \\
\hline$\%$ with $\mathrm{A}_{\mathrm{IC}}<7.0 \%$ & 55.6 & 37.2 & $<0.001$ \\
\hline$\%$ with $\mathrm{A}_{\mathrm{IC}}>7.5 \%$ & 25.4 & 43.4 & $<0.001$ \\
\hline$\%$ with $A_{1 C}>8.0 \%$ & 13.5 & 27.1 & $<0.001$ \\
\hline Duration of hypertension (\%) & & & $<0.001$ \\
\hline$<\mathrm{l}$ yr & 5.6 & 3.2 & \\
\hline $1-5 y r$ & 27.0 & 16.9 & \\
\hline $5-10 \mathrm{yr}$ & 30.2 & 29.4 & \\
\hline$>10 \mathrm{yr}$ & 37.1 & 50.5 & \\
\hline Number of antihypertensives, mean \pm SD & $1.9 \pm 1.0$ & $2.2 \pm 1.0$ & $<0.001$ \\
\hline$\%$ monotherapy & 43.9 & 27.2 & $<0.001$ \\
\hline$\%$ dual therapy & 31.7 & 36.6 & \\
\hline$\%$ triple therapy or more & 24.4 & 36.3 & \\
\hline $\mathrm{BP}<\mathrm{I} 40 / 90 \mathrm{mmHg}$ office (\%) & 65.4 & 51.2 & $<0.001$ \\
\hline $\mathrm{BP}<135 / 85 \mathrm{mmHg}$ ambulatory (\%) & 64.9 & 45.3 & $<0.001$ \\
\hline Smokers (\%) & 8.1 & 12.5 & 0.005 \\
\hline Dyslipidemia (treated) (\%) & 64.0 & 71.2 & 0.002 \\
\hline$\%$ of patients with any diabetic complication & 41.1 & 56.1 & $<0.001$ \\
\hline Microvascular complications (\%) & 22.9 & 39.7 & $<0.001$ \\
\hline Retinopathy & 6.8 & 11.7 & 0.001 \\
\hline Nephropathy & 15.8 & 26.8 & $<0.001$ \\
\hline Neuropathy & 5.6 & 12.7 & $<0.001$ \\
\hline Diabetic foot & 1.4 & 2.4 & 0.18 \\
\hline Macrovascular complications (\%) & 25.5 & 33.9 & $<0.001$ \\
\hline Coronary disease & 18.8 & 22.1 & 0.106 \\
\hline Cerebrovascular disease & 3.5 & 6.5 & 0.008 \\
\hline Lower limb arteriopathy & 5.9 & 13.5 & $<0.001$ \\
\hline $\mathrm{CHF}(\%)$ & 1.0 & 4.7 & $<0.001$ \\
\hline COPD (\%) & 3.3 & 7.7 & $<0.001$ \\
\hline Osteoarticular disorder (\%) & 15.1 & 43.9 & $<0.001$ \\
\hline
\end{tabular}

Note: Comparisons between both groups (active patients and inactive patients): chi-square test for qualitative variables; Student's $t$-test for quantitative variables.

Abbreviations: RG, Ricci-Gagnon; SD, standard deviation; yr, years; BMI, body mass index; SPC, socioprofessional category; OAD, oral antidiabetic agents; HbA hemoglobin; BP, blood pressure; CHF, chronic heart failure; COPD, chronic obstructive pulmonary disease. 
Table 2 Physical activity scores of the patients in the active and inactive cohorts using RG and IPAQ-SF questionnaires

\begin{tabular}{|c|c|c|c|}
\hline Physical activity & $\begin{array}{l}\text { Active patients, } \\
\text { RG } \geq 16(\mathrm{~N}=628)\end{array}$ & $\begin{array}{l}\text { Inactive patients, } \\
\text { RG }<16(\mathrm{~N}=1,138)\end{array}$ & $P$-value \\
\hline \multicolumn{4}{|l|}{ RG questionnaire } \\
\hline Total RG score (mean \pm SD) & $24.6 \pm 3.8$ & $8.6 \pm 2.9$ & $<0.00$ I \\
\hline Median & 24 & 8 & \\
\hline$\%$ with leisure and exercise PA & 97.9 & 9.6 & $<0.00$ I \\
\hline Score for leisure and exercise PA & $14.4 \pm 2.8$ & $1.7 \pm 2.5$ & $<0.001$ \\
\hline Score for daily activities & $10.2 \pm 2.8$ & $6.9 \pm 2.4$ & $<0.00$ I \\
\hline \multicolumn{4}{|l|}{ IPAQ-SF questionnaire } \\
\hline \multicolumn{4}{|l|}{ Total IPAQ-SF score } \\
\hline MET-min/wk; mean \pm SD & $4,70 I \pm 4,5 I I$ & $\mathrm{I}, 60 \mathrm{I} \pm 2,372$ & $<0.001$ \\
\hline Median & 3,213 & 803 & \\
\hline \multicolumn{4}{|l|}{ IPAQ vigorous $\mathrm{PA}$} \\
\hline$\%$ with vigorous PA & 59.5 & 9.6 & $<0.00 \mathrm{I}$ \\
\hline MET-min/wk; mean \pm SD & $2,053 \pm 3,648$ & $282 \pm 1,378$ & $<0.00$ I \\
\hline Median & 960 & 0 & \\
\hline \multicolumn{4}{|l|}{ IPAQ moderate PA } \\
\hline$\%$ with moderate PA & 94.1 & 59.3 & $<0.00 \mathrm{I}$ \\
\hline $\mathrm{MET}-\mathrm{min} / \mathrm{wk} ;$ mean $\pm \mathrm{SD}$ & $\mathrm{I}, 468 \pm I, 493$ & $692 \pm 1,268$ & $<0.001$ \\
\hline Median & 960 & 240 & \\
\hline \multicolumn{4}{|l|}{ Walking } \\
\hline $\mathrm{min} / \mathrm{d} ;$ mean $\pm \mathrm{SD}$ & $69.3 \pm 61.3$ & $44.1 \pm 47.6$ & $<0.001$ \\
\hline $\mathrm{MET}-\mathrm{min} / \mathrm{wk} ;$ mean $\pm \mathrm{SD}$ & $1,243 \pm 1,265$ & $631 \pm 911$ & $<0.001$ \\
\hline Median & 891 & 347 & \\
\hline \multicolumn{4}{|l|}{ Sedentary } \\
\hline$\%(\geq 8 \mathrm{~h} / \mathrm{d}$ sitting time $)$ & 37.8 & 64.2 & $<0.00 \mathrm{I}$ \\
\hline $\mathrm{h} / \mathrm{d} ;$ mean $\pm \mathrm{SD}$ & $7.2 \pm 3.1$ & $9.3 \pm 3.6$ & $<0.001$ \\
\hline Median & 7.0 & 9.0 & \\
\hline
\end{tabular}

Note: Comparisons between both groups (active patients and inactive patients): chi-square test for qualitative variables; Student's $t$-test for quantitative variables.

Abbreviations: RG, Ricci-Gagnon; PA, physical activity; IPAQ, International Physical Activity Questionnaire; min, minutes; wk, weeks; h, hour; d, day; MET, metabolic equivalent task; SD, standard deviation.

in the active cohort, to have an active physician, a lower treatment burden, and fewer barriers to PA.

Similar results were observed when conducting supportive analyses in the cohorts of patients reclassified a posteriori as active and inactive according to the IPAQ-SF questionnaire (data not shown).

\section{Analysis of barriers and motivations for patients}

Self-questionnaires ranking a list of barriers and motivations were completed by active $(n=556)$ and inactive patients ( $n=411$ ) according to both RG and IPAQ-SF questionnaires, as described in the Methods section. On a scale of 1

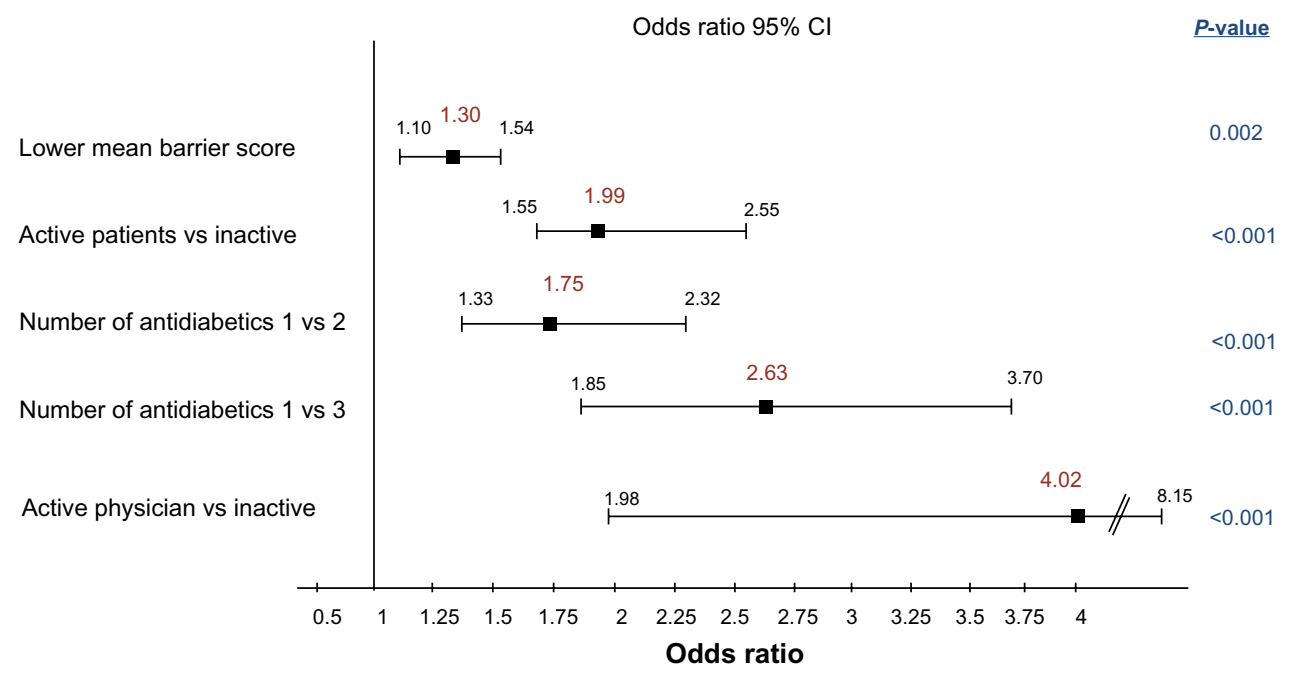

Figure I Multivariate analysis - factors significantly associated with control of both diabetes and hypertension.

Note: Odds ratio is shown with $95 \% \mathrm{Cl}$ for significant covariates.

Abbreviation: $\mathrm{Cl}$, confidence interval. 
("fully disagree") to 5 ("fully agree") for each item, the active cohort had a mean barrier score of $2.4 \pm 0.8$ and a mean motivation score of $3.2 \pm 0.6$, while the inactive cohort had a higher mean barrier score of $2.8 \pm 0.7(P<0.001$ vs active) and a lower mean motivation score of $2.6 \pm 0.8(P<0.001$ vs active).

The role of the physician also emerged in the motivations (reassurance on potential health issues and training on potential risks such as hypoglycemia, as well as the importance of a specific request from the physician and his monitoring of the PA), while a negative self-image was the highest ranked barrier for the inactive patients, followed by the lack of support and encouragement, and by medical concerns and fear of injury (Figure 2A and B).

\section{Analysis of physicians' questionnaires}

All the physicians were fully aware of the effectiveness of PA in the management of diabetes and hypertension.

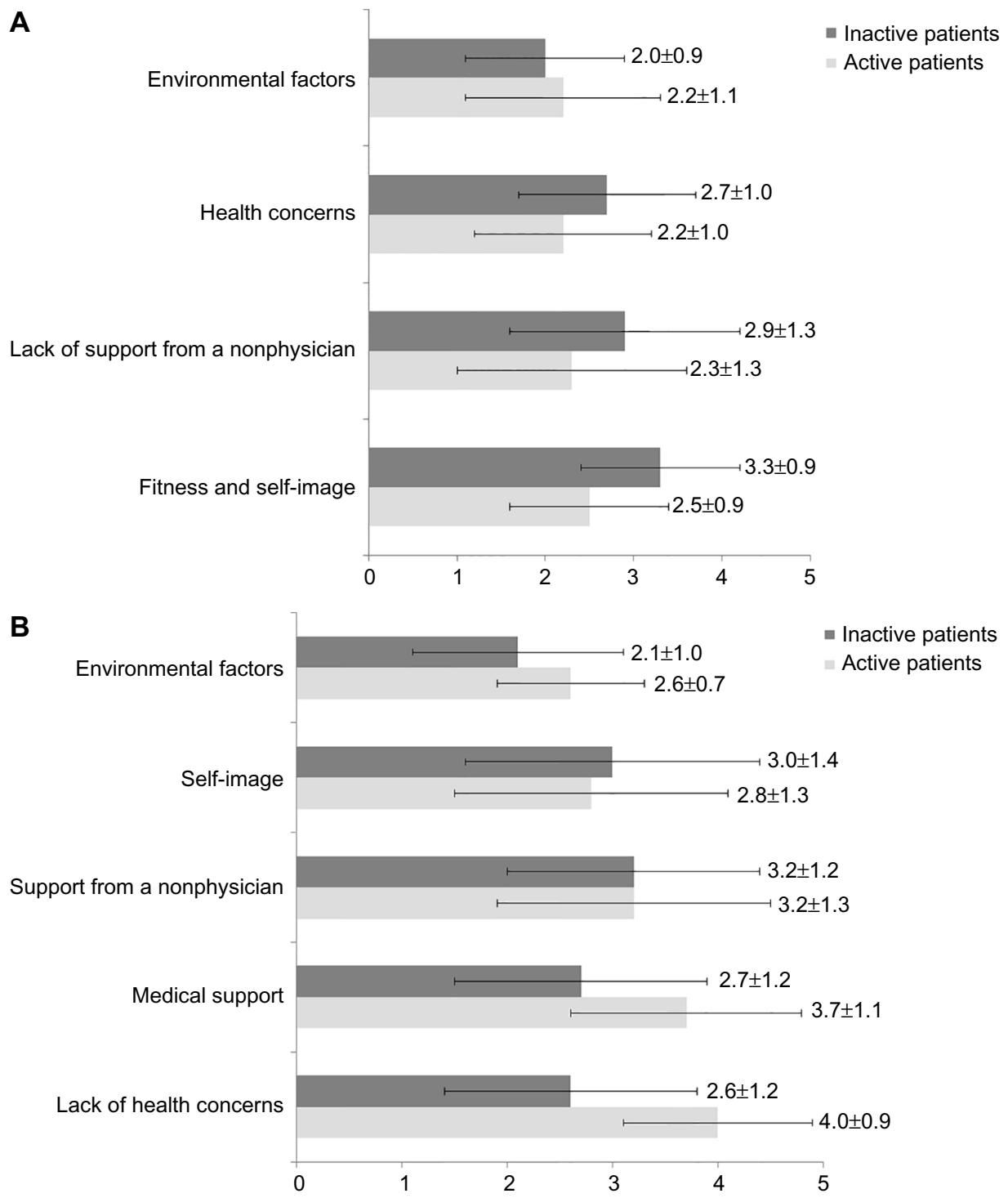

Figure 2 Barriers and motivations to physical activity ranked by the patients.

Notes: (A) Barriers: Barriers were ranked on a scale of I (fully disagree) to 5 (fully agree). Mean (and SD) responses from active patients are shown in light grey and that of inactive patients in dark grey. Items were: I) fitness and self-image (feeling too tired, too fat, not feeling like it, feeling unfit, feeling self-conscious about one's look); 2) lack of support from a nonphysician (nobody to exercise with, nobody encouraging); 3) health concerns (fear of hypoglycemia, fear of BP rise, musculoskeletal disorders, fear of heart attack, fear of injury); 4) environmental factors (lack of infrastructures close by, lack of parks close by, lack of time, too costly). (B) Motivations: Motivations were ranked on a scale of I (fully disagree) to 5 (fully agree). Mean (and SD) responses from active patients are shown in light grey and that of inactive patients in dark grey. Items were: I) lack of health concerns (no fear of any medical risk being trained on how to prevent hypoglycemia); 2 ) medical support (direct request from the physician, regular monitoring of patients' PA from the physician); 3) support from a nonphysician (someone to exercise with, someone encouraging); 4) self-image (having sufficiently lost weight); 5) environmental factors (sufficient infrastructures/parks available close by, pedometer to use, internet or smartphone advices, advice from a coach, having sufficient time).

Abbreviations: SD, standard deviation; BP, blood pressure; PA, physical activity. 
However, for the physicians (both cardiologists and DB), a lower priority was accorded to PA, after dietary advice and advice to stop smoking. All declared counseling their patients about PA and about $65 \%$ also declared mentioning PA in their correspondence to GPs, but over 50\% of them spent $<5$ minutes on this topic.

They were more inclined to prescribe PA in patients already expressing some motivation. The physicians' main barrier to prescription was the presence of osteoarticular disorders.

\section{Discussion}

In this large population of patients with T2DM and hypertension, the active cohort - as assessed by both RG and IPAQ-SF - was slightly younger and markedly healthier than the inactive cohort: less obesity, more recent disease, and fewer complications and comorbidities. The major difference in total PA scores was driven by the quantity of regular exercise/or leisure-type $\mathrm{PA}$ (with $\mathrm{RG}$ ) or by vigorous activities (with IPAQ-SF). Patients in the active cohort were more likely to reach both BP and glycemic targets and this was found to be driven not only by the patients' PA and barriers but also by the physicians' PA.

It is of interest to look at PA data from similar populations, such as the recently published Échantillon National Témoin REprésentatif des personnes Diabétiques (ENTRED-PA), a national survey of French patients with T2DM pharmacologically treated. ${ }^{11}$ PA data from 724 ENTRED respondents, who had demographic and clinical characteristics generally similar to our MOBILE population, were analyzed. Their median total score was 2,079 (Q1 =893, Q3 =3,915) MET-min/ wk, which falls between that of our inactive cohort (803 MET$\mathrm{min} / \mathrm{wk}$ ) and the active one (3,213 MET-min/wk). Domestic chores were always the main contributor to total PA in this population. ${ }^{11}$ While this domain of domestic PA (considered as PA of moderate intensity ${ }^{12}$ ) was not specifically assessed in our study, we can draw a parallel with the score for moderate intensity activities in MOBILE. The total median PA score of the ENTRED diabetic population was, as expected, substantially lower than that found in the general French population from the EUPASS research project (median IPAQ-SF: 3,826 MET-min/wk). ${ }^{13}$ However, finding that $84 \%$ of the ENTRED patients were still well above the current guidelines for PA is remarkably discordant with current knowledge in both the diabetic $^{14}$ and the general population. ${ }^{15}$ In this context, the median level of IPAQ-SF (803 MET-min/wk) in our "inactive" MOBILE cohort ( $59 \%$ of patients with $\geq 600 \mathrm{MET}-\mathrm{min} / \mathrm{wk}$ ) is not so surprising. This apparent overestimation of the PA from the patient's perspective vs the recommendations could be due to an "interpretation gray-zone" in the recommendations, ie, $600 \mathrm{MET}-\mathrm{min} / \mathrm{wk}$ should be in addition to routine activities of daily living. ${ }^{3,16}$

The IPAQ-SF also allowed further insight into sedentary behavior, another important area for preventive medicine, as illustrated by a large prospective study of US adults (53,440 men and 69,776 women). ${ }^{17}$ This study showed that the time spent sitting was independently associated with total mortality, regardless of PA level. ${ }^{17}$ In MOBILE, we showed that patients in the inactive cohort not only had a lower PA score but also a higher sedentary score, and that overall, the sedentary score was inversely correlated to PA as measured by the IPAQ-SF. Furthermore, the distribution of activities while sitting was different between the two cohorts: while the inactive cohort spent significantly more time watching TV (during the week as well as weekends), they spent less time sitting at a computer. TV time has also been linked with specific dietary behaviors, such as a higher likelihood of snacking (mostly junk food). ${ }^{18,19}$ This TV vs computer time is probably associated with a lower education and socioeconomic level, which has previously been shown to be correlated with less PA. ${ }^{20}$

In view of the demographic and clinical differences between the active vs inactive cohort, it was not surprising to see that glycemic and BP control was more often achieved in the active patients, despite lower treatment scores. As expected, multivariate analysis confirmed that active patients were twice as likely to reach glycemic and BP targets, as well as those with a lower treatment burden (monotherapy vs dual or triple therapy). This lower treatment burden may be indicative of a less severe and less advanced disease and/or of a higher overall compliance with their care. Several other factors emerged through multivariate analysis as being significantly associated with the control of both diabetes and hypertension: barriers, physicians' PA (Figure 1). Predictably, patients expressing fewer barriers to PA were also more likely to achieve both targets. ${ }^{21}$ The strongest correlate was that participants with a physically active physician were four times more likely to be controlled for both targets vs those with an inactive physician. This could be related to the fact that physicians who engage in regular PA have themselves fewer barriers to PA and are, therefore, more likely to positively influence their patients' involvement in regular PA, as already shown in the Barriers to Physical Activity in Diabetes study. ${ }^{22}$ It has also been shown previously that physicians who exercise are more likely to effectively counsel their patients to exercise and are more convincing in doing so. ${ }^{23}$ This raises the issue of the 
quality of physician-patient communication, as illustrated in the French multinational second Diabetes, Attitudes, Wishes and Needs study. ${ }^{24}$

The influence of the physician emerged again as the most important motivation in the active cohort: by providing reassurance on potential health issues (restoring confidence in their health, reassurance about fear of injury and hypoglycemia), along with the physician's involvement and interest (specific request and monitoring of the patient's PA) (Figure 2B).

In MOBILE, those who exercised less reported significantly more barriers for PA and their mean motivation score was markedly lower $(2.6 \pm 0.8$ vs $3.2 \pm 0.6 ; P<0.001)$. They generally felt too unfit, too tired, and too fat to be able to start moving: a vicious cycle from which they find it difficult to escape. To help them do so, they would need a program including weight management and dealing with how to improve feelings of physical and mental well-being. Lack of company and encouragement from others was also highly ranked as a barrier, suggesting the importance of promoting social relationships associated with exercise (Figure 2A).

Investigating the multiple factors that contribute to the propensity of being physically inactive throughout life is an important area of research ${ }^{25}$ and has been the subject of studies in various populations trying to understand barriers and enablers of PA. ${ }^{20,21,26-30}$

In older adults (aged $\geq 65$ years) from the 2009 New South Wales Falls Prevention Survey, after adjusting for sex, age, BMI, and education, participants who listed ill health ( $52 \%$; odds ratio $[\mathrm{OR}]=0.56,95 \% \mathrm{CI} 0.45-0.70)$ as a barrier, or people to exercise with $(4 \%$; OR $=0.49,95 \%$ CI $0.27-0.88)$ as an enabler were significantly less likely to meet PA recommendations. ${ }^{28}$ Another study in older individuals (median age of 77 years) in Germany ${ }^{29}$ analyzed barriers to PA for those who stated that they did not get enough PA $(n=286)$. The three most frequently cited barriers were poor health (57.7\%), lack of company (43.0\%), and lack of interest (36.7\%). ${ }^{29}$ These main barriers resemble MOBILE item 1 (a mix of feeling unfit and not feeling like it) and 2 (nobody to exercise with, nobody encouraging) which ranked as highest barriers in the inactive cohort.

As expected, health status or perceived health emerged as an important factor in MOBILE, as illustrated by the high number of patients reporting fear of injury and health concerns as barriers. In ENTRED, a better health perception was associated with more PA $(\mathrm{OR}=2.12,95 \% \mathrm{CI}=1.18-3.83)$, independent of age and the presence of diabetic complications. ${ }^{11}$ In a survey among 1,848 randomly selected rural Colorado adult residents, fear of injury with PA was shown to be greater in adults with diabetes than in adults without, and it affected the preferred form of activity in diabetes, ie, walking. ${ }^{31}$ Fear of hypoglycemia has previously been described as a significant barrier to PA. ${ }^{32}$ Although it did not emerge as such in MOBILE, patients who were properly trained to prevent hypoglycemia flagged it up as a strong motivation. However, these fears have been shown to be largely unsubstantiated in patients with T2DM in a Cochrane meta-analysis ${ }^{33}$ and in cardiac patients and after coronary stenting. ${ }^{34,35}$

Lastly, cost and environmental factors outside the health sector (parks and availability of various devices, such as pedometers or apps/widgets) did not rank high in MOBILE. This may in part be due to the mean age of our population, unfamiliar with the use of apps, and the fact that most of these devices are not tailored to their individual interests, are not sufficiently interactive, and are thus far less important for these patients than an informed discussion and individual exercise counseling with their own physician.

Our study has several strengths and limitations.

One of the strengths of MOBILE is the large sample size and that it reports on questionnaires from both patients and their physicians exploring barriers and motivations in active and inactive patients in parallel.

Furthermore, the inverse relationship between sedentary behavior and PA has seldom been investigated. It could be interesting to further study this relationship and determine if decreasing the time spent in sedentary behavior affects PA quantity or quality.

One limitation of the study is that caution should be exercised when interpreting the PA level of our population. While the IPAQ-SF has previously been validated compared to objective methods and its overall reliability assessed across 12 countries, ${ }^{9}$ the RG questionnaire has not. However, this choice was based primarily on the simplicity of the RG questionnaire making it easier to use as a screening tool. Furthermore, it is known that subjective assessment of PA by any self-questionnaire is susceptible to social approval bias that may lead to a substantial over-reporting of PA. ${ }^{36}$ In addition, it has been shown that the IPAQ questionnaire is particularly susceptible to PA overestimation. ${ }^{37}$

While our study population was generally representative of patients with T2DM and hypertension in France, there might be a physician participation bias (ie, it is possible that more active physicians, aware of the importance of PA, accepted to participate).

Finally, it was interesting to explore the independent correlates to reach both glycemic and BP target, but this does not imply causal relationship. 


\section{Conclusion}

The main difference in the motivations expressed by the active vs inactive cohorts lies in the role of the physician: his/her reassurance on perceived health issues and the active role they play in prescribing and monitoring PA as an integral part in managing T2DM and hypertension. Physicians should take into account the motivations and barriers to PA of their patients and tailor advice to their specific needs, to reduce their perceived constraints to PA. Thus, physicians play a central role in PA counseling and should really consider PA prescription as seriously as any drug prescription, with the same need to monitor compliance and the response effect. However, while all physicians appeared to be convinced of the importance of PA, and all declare counseling PA to their patients, they currently do not have enough time to spend on this topic in daily practice. Strategies to promote and monitor PA should include additional measures beyond the physicianpatient relationship, such as new interactive technologies, education and improved societal awareness.

\section{Acknowledgment}

This work was funded by Novartis Pharmaceuticals Corporation. The authors would like to thank all the patients and investigators at participating sites, and Felicity Neilson for her valuable suggestions to improve this article.

\section{Disclosure}

M Duclos has received fees for consultancy, advisory boards, conference, travel, or accommodation from Novartis, NovoNordisk and Sanofi. N Postel-Vinay has received fees for clinical investigations from Novartis. $\mathrm{S}$ di Nicola is shareholder in Inferential, a provider of biostatistical consulting services working with pharmaceutical companies including Novartis. B Fiquet, S Quéré and S Dejager are employees of Novartis Pharma SAS. The authors report no other conflicts of interest in this work.

\section{References}

1. Colberg SR, Sigal RJ, Fernhall B, et al; American College of Sports Medicine; American Diabetes Association. Exercise and type 2 diabetes: the American College of Sports Medicine and the American Diabetes Association: joint position statement. Diabetes Care. 2010;33(12): e147-e167.

2. Roberts CK, Barnard RJ. Effects of exercise and diet on chronic disease. J Appl Physiol (1985). 2005;98(1):3-30.

3. Duclos M, Oppert JM, Verges B, et al; SFD Diabetes and Physical Activity Working Group. Physical activity and type 2 diabetes. Recommendations of the SFD (Francophone Diabetes Society) diabetes and physical activity working group. Diabetes Metab. 2013;39(3):205-216.

4. Duclos M, Virally ML, Dejager S. Exercise in the management of type 2 diabetes mellitus: what are the benefits and how does it work? Phys Sportsmed. 2011;39(2):98-106.
5. Cornelissen VA, Smart NA. Exercise training for blood pressure: a systematic review and meta-analysis. J Am Heart Assoc. 2013; 2(1):e004473.

6. Wen $\mathrm{CP}, \mathrm{Wu} \mathrm{X}$. Stressing harms of physical inactivity to promote exercise. Lancet. 2012;380(9838):192-193.

7. Ekelund U, Ward HA, Norat T, et al. Physical activity and allcause mortality across levels of overall and abdominal adiposity in European men and women: the European Prospective Investigation into Cancer and Nutrition Study (EPIC). Am J Clin Nutr. 2015;101(3): 613-621.

8. Leitzmann MF, Park Y, Blair A, et al. Physical activity recommendations and decreased risk of mortality. Arch Intern Med. 2007;167(22): 2453-2460.

9. Craig CL, Marshall AL, Sjostrom M, et al. International physical activity questionnaire: 12-country reliability and validity. Med Sci Sports Exerc. 2003;35(8):1381-1395.

10. Haskell WL, Lee IM, Pate RR, et al. Physical activity and public health: updated recommendation for adults from the American College of Sports Medicine and the American Heart Association. Med Sci Sports Exerc. 2007;39(8):1423-1434.

11. Cloix L, Caille A, Helmer C, et al. Physical activity at home, at leisure, during transportation and at work in French adults with type 2 diabetes: the ENTRED physical activity study. Diabetes Metab. 2015;41(1): $37-44$.

12. Ainsworth BE, Haskell WL, Whitt MC, et al. Compendium of physical activities: an update of activity codes and MET intensities. Med Sci Sports Exerc. 2000;32(9 Suppl):S498-S504.

13. Rütten A, Ziemainz H, Schena F, et al. Using different physical activity measurements in eight European countries. Results of the European Physical Activity Surveillance System (EUPASS) time series survey. Public Health Nutr. 2003;6(4):371-376.

14. Resnick HE, Foster GL, Bardsley J, Ratner RE. Achievement of American Diabetes Association clinical practice recommendations among US adults with diabetes, 1999-2002: the National Health and Nutrition Examination Survey. Diabetes Care. 2006;29(3):531-537.

15. Salanave B, Vernay M, Szego E, et al. Physical activity patterns in the French 18-74-year-old population: French nutrition and health survey (Etude Nationale Nutrition Sante, ENNS) 2006-2007. Public Health Nutr. 2012;15(11):2054-2059.

16. Haskell WL, Lee IM, Pate RR, et al. Physical activity and public health: updated recommendation for adults from the American College of Sports Medicine and the American Heart Association. Circulation. 2007;116(9):1081-1093.

17. Patel AV, Bernstein L, Deka A, et al. Leisure time spent sitting in relation to total mortality in a prospective cohort of US adults. Am J Epidemiol. 2010;172(4):419-429.

18. Chaput JP, Klingenberg L, Sjodin A. Do all sedentary activities lead to weight gain: sleep does not. Curr Opin Clin Nutr Metab Care. 2010; 13(6):601-607.

19. Chaput JP, Klingenberg L, Astrup A, Sjodin AM. Modern sedentary activities promote overconsumption of food in our current obesogenic environment. Obes Rev. 2011;12(5):e12-e20.

20. Donahue KE, Mielenz TJ, Sloane PD, Callahan LF, Devellis RF. Identifying supports and barriers to physical activity in patients at risk for diabetes. Prev Chronic Dis. 2006;3(4):A119.

21. Korkiakangas EE, Alahuhta MA, Laitinen JH. Barriers to regular exercise among adults at high risk or diagnosed with type 2 diabetes: a systematic review. Health Promot Int. 2009;24(4):416-427.

22. Duclos M, Coudeyre E, Ouchchane L. General practitioners' barriers to physical activity negatively influence type 2 diabetic patients' involvement in regular physical activity. Diabetes Care. 2011;34(7):e122.

23. Abramson S, Stein J, Schaufele M, Frates E, Rogan S. Personal exercise habits and counseling practices of primary care physicians: a national survey. Clin J Sport Med. 2000;10(1):40-48.

24. Reach G, Consoli SM, Halimi S, et al. The multinational second diabetes, attitudes, wishes and needs study: results of the French survey. Patient Prefer Adherence. 2015;9:289-297. 
25. Bauman AE, Reis RS, Sallis JF, Wells JC, Loos RJ, Martin BW. Correlates of physical activity: why are some people physically active and others not? Lancet. 2012;380(9838):258-271.

26. Aaltonen S, Kujala UM, Kaprio J. Factors behind leisure-time physical activity behavior based on Finnish twin studies: the role of genetic and environmental influences and the role of motives. Biomed Res Int. 2014; 2014:931820.

27. Korkiakangas EE, Alahuhta MA, Husman PM, KeinanenKiukaanniemi S, Taanila AM, Laitinen JH. Motivators and barriers to exercise among adults with a high risk of type 2 diabetes - a qualitative study. Scand J Caring Sci. 2011;25(1):62-69.

28. Macniven R, Pye V, Merom D, et al. Barriers and enablers to physical activity among older Australians who want to increase their physical activity levels. J Phys Act Health. 2014;11(7):1420-1429.

29. Moschny A, Platen P, Klaassen-Mielke R, Trampisch U, Hinrichs T. Barriers to physical activity in older adults in Germany: a cross-sectional study. Int J Behav Nutr Phys Act. 2011;8:121.

30. Korkiakangas E, Taanila AM, Keinanen-Kiukaanniemi S. Motivation to physical activity among adults with high risk of type 2 diabetes who participated in the Oulu substudy of the Finnish Diabetes Prevention Study. Health Soc Care Community. 2011;19(1):15-22.

31. Huebschmann AG, Crane LA, Belansky ES, Scarbro S, Marshall JA, Regensteiner JG. Fear of injury with physical activity is greater in adults with diabetes than in adults without diabetes. Diabetes Care. 2011;34(8):1717-1722.
32. Swift CS, Armstrong JE, Beerman KA, Campbell RK, Pond-Smith D. Attitudes and beliefs about exercise among persons with non-insulindependent diabetes. Diabetes Educ. 1995;21(6):533-540.

33. Thomas DE, Elliott EJ, Naughton GA. Exercise for type 2 diabetes mellitus. Cochrane Database Syst Rev. 2006;3:CD002968.

34. Iliou MC, Pavy B, Martinez J, Corone S, Meurin P, Tuppin P. Exercise training is safe after coronary stenting: a prospective multicentre study. Eur J Prev Cardiol. 2015;22(1):27-34.

35. Pavy B, Iliou MC, Meurin P, Tabet JY, Corone S. Safety of exercise training for cardiac patients: results of the French registry of complications during cardiac rehabilitation. Arch Intern Med. 2006;166(21): 2329-2334.

36. Adams SA, Matthews CE, Ebbeling CB, et al. The effect of social desirability and social approval on self-reports of physical activity. Am J Epidemiol. 2005;161(4):389-398.

37. Lee PH, Yu YY, McDowell I, Leung GM, Lam TH, Stewart SM. Performance of the international physical activity questionnaire (short form) in subgroups of the Hong Kong Chinese population. Int J Behav Nutr Phys Act. 2011;8:81.
Vascular Health and Risk Management

\section{Publish your work in this journal}

Vascular Health and Risk Management is an international, peerreviewed journal of therapeutics and risk management, focusing on concise rapid reporting of clinical studies on the processes involved in the maintenance of vascular health; the monitoring, prevention and treatment of vascular disease and its sequelae; and the involvement of

\section{Dovepress}

metabolic disorders, particularly diabetes. This journal is indexed on PubMed Central and MedLine. The manuscript management system is completely online and includes a very quick and fair peer-review system, which is all easy to use. Visit http://www.dovepress.com/ testimonials.php to read real quotes from published authors. 